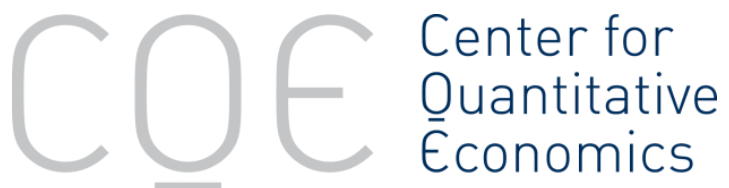

\section{Short selling constraints and stock returns volatility: empirical evidence from the German stock market}

Martin T. Bohl, Gerrit Reher und Bernd Wilfling ${ }^{\dagger}$

$45 / 2016$

${ }^{\dagger}$ Department of Economics, University of Münster, Germany 


\title{
Short selling constraints and stock returns volatility: empirical evidence from the German stock market
}

\author{
Martin T. Bohl ${ }^{a}$, Gerrit Reher ${ }^{\text {a }}$, Bernd Wilfling ${ }^{a, *}$ \\ ${ }^{a}$ Westfälische Wilhelms-Universität Münster, Department of Economics, Am Stadtgraben 9, \\ 48143 Münster, Germany
}

(Date of this version: January 15, 2016)

\begin{abstract}
In this paper we focus on the impact of short selling restrictions on stock returns volatility. To assess potential effects econometrically we apply two distinct versions of an asymmetric Markov-switching GARCH model to the recent short selling bans on stocks of financial enterprises in Germany. We find empirical evidence that the financial crisis is accompanied by an increase in volatility persistence and that this effect is particularly pronounced for those stocks that are subject to short selling constraints. We interpret this finding as evidence of a destabilizing impact of short selling constraints on stock returns volatility.
\end{abstract}

JEL-classification codes: C5, G10, G18.

Key words: Financial market regulation; short selling constraints; stock returns volatility; Markov-switching GARCH models.

${ }^{*}$ Corresponding author. Phone: $+49-251-83$ - 25040, fax: +49 - 251 -83 - 25042, e-mail address: bernd.wilfling@wiwi.uni-muenster.de 


\title{
Short selling constraints and stock returns volatility: empirical evidence from the German stock market
}

\begin{abstract}
In this paper we focus on the impact of short selling restrictions on stock returns volatility. To assess potential effects econometrically we apply two distinct versions of an asymmetric Markov-switching GARCH model to the recent short selling bans on stocks of financial enterprises in Germany. We find empirical evidence that the financial crisis is accompanied by an increase in volatility persistence and that this effect is particularly pronounced for those stocks that are subject to short selling constraints. We interpret this finding as evidence of a destabilizing impact of short selling constraints on stock returns volatility.
\end{abstract}

JEL-classification codes: C5, G10, G18.

Key words: Financial market regulation; short selling constraints; stock returns volatility; Markov-switching GARCH models. 


\section{Introduction}

During the financial crisis 2008/2009 and the Greek crisis 2009/2010 governments in many countries imposed limitations on short selling activities to displace short sellers and prevent further declines in stock prices. While governments, regulators, and the media blame short sellers for reinforcing stock market downturns, academic research mostly finds distortions of short selling restrictions on market efficiency, liquidity and pricing. Although there is no recent survey available, Bris et al. (2007) provide many of the most important references on the topic. More recent treatments on this issue (Beber et al., 2015; Boehmer et al., 2015), do not change the conclusion of the destroying effects of short selling bans on market quality.

Surprisingly little is known about the impact of short selling restrictions on stock returns volatility. As an exception, Bohl et al. (2012) investigate Taiwanese stock market data applying asymmetric GARCH models adjusted by a dummy variable and a Markov switching GARCH model. Their empirical evidence shows that short selling restrictions raise stock returns volatility. The increase in volatility can be explained by the limited ability of investors to find the fundamental price. Consequently, short selling bans contribute to a destabilization of stock prices during periods of market downturns and even exaggerate stock price declines. Hence, from a regulatory point of view short selling bans are counterproductive.

Taiwan's relatively long period of short selling bans enables Bohl et al. (2012) to uncover the impact of short selling restrictions on stock returns volatility. However, the bulk of the literature relies on cross-sectional regressions and event type studies given the short periods of short selling bans regulatory institutions mostly impose. Germany provides another sensible testing ground for a time series analysis of short selling bans' impact on stock returns volatility because short selling bans were established from September 2008 to January 2010 and then reinstalled from May 2010 onwards on stocks of financial enterprises. For this period we apply two variants of an asymmetric Markov switching GARCH model as developed in Reher and Wilfling (2016).

Our econometric technique has several advantages over the dummy variable approaches 
and the standard Markov-switching models routinely used in the literature. Dummy variable approaches try to capture structural breaks in the volatility process of stock returns by exogenously setting the point in time when the structural break is assumed to have taken place. In our empirical application a natural date for this break appears to be the start of the short selling ban under consideration. However, as Bohl et al. (2016) argue in a recent study, this simple strategy of fixing the break point date can be challenged, since it imposes an abrupt one-step and irreversible change in the volatility process and completely neglects investors' forwardlooking expectations about the potential future imposition of the short selling ban, which may affect volatility. Therefore, in order to capture any kind of gradual adjustment from one volatility regime to another, Bohl et al. (2016) advocate the use of a Markov-switching GARCH framework, which endogenously models switches between alternative volatility regimes without imposing a priori a predetermined sequence of volatility regime change.

Compared to the conventional Markov-switching GARCH models used in the previous literature, the Reher and Wilfling (2016) framework employed in our empirical analysis below is advantageous for two reasons. (1) This Markov-switching GARCH model is able to capture any type of regime-specific asymmetric volatility effects, and (2), it enables us to estimate alternative GARCH equations of entirely different functional forms across the volatility regimes (for example an EGARCH specification in the first volatility regime and a TGARCH specification in the second).

The remainder of the paper is structured as follows. Section 2 considers the Markovswitching GARCH framework. Section 3 provides the data and the empirical findings, while Section 4 concludes.

\section{A Markov-switching GARCH framework}

In this section we specify our econometric model. Since we aim to investigate as to what extent the restrictions of naked short sales may have a stabilizing impact on the stock market, we focus on measuring stock returns volatility before, during, and after restriction periods. Movements 
of volatility through time are typically well-captured by some sort of GARCH model. However, the fact that we expect short selling constraints to induce a change in the behavior of market participants suggests the estimation of a Markov-switching GARCH model.

In our empirical analysis below we estimate two distinct Markov-switching GARCH specifications which are special cases of a very general two-regime Markov-switching GARCH framework developed by Reher and Wilfling (2016). In our first specification one Markov-regime is governed by an EGARCH process (see Nelson, 1991), whereas the second Markov-regime is governed by a TGARCH equation (see Zakoian, 1994). While we refer to this specification as a Markov-switching EGARCH-TGARCH model, our second model variant assumes distinct TGARCH processes in both Markov-regimes, suggesting the term TGARCH-TGARCH for this specification.

To build up our econometric specifications we assume that the data generating process (DGP) of the stock price return $r_{t}$ is affected by an unobserved latent random variable $S_{t}$ representing the regime the DGP is in at time $t$. As mentioned above, we assume only two distinct regimes 1 and 2 at any point in time, that is we assume either $S_{t}=1$ or $S_{t}=2$ for all $t=1,2, \ldots$. Since we focus on the volatility effects of short selling restrictions, we model a constant, non-switching mean $\lambda$ across both Markov-regimes and only let the volatility processes switch between the regimes.

To this end we let the return dynamics depend on the regime indicator $S_{t}=i, i=1,2$ and specify

$$
r_{t+1}=\lambda+\sqrt{h_{i, t}} \epsilon_{t+1}
$$

In Eq. (1) $\left\{\epsilon_{t}\right\}$ is an i.i.d. process of standard normal variates, while $h_{i, t}$ represents the conditional variance in regime $i$. Following Reher and Wilfling (2016), we define our variance equation in its most general form as

$$
h_{i, t}=\left\{\begin{array}{ll}
{\left[\omega_{i}+\alpha_{i}{\sqrt{h_{t-1}^{(i)}}}^{\mu_{i}} f_{i}^{\nu_{i}}\left(\delta_{t}^{(i)}\right)+\beta_{i}{\sqrt{h_{t-1}^{(i)}}}^{\mu_{i}}\right]^{2 / \mu_{i}}} & \text { for } \mu_{i}>0 \\
{\left[\exp \left\{\omega_{i}+\alpha_{i} f_{i}^{\nu_{i}}\left(\delta_{t}^{(i)}\right)+\beta_{i} \ln \left(\sqrt{h_{t-1}^{(i)}}\right)\right\}\right]^{2} \text { for } \mu_{i}=0}
\end{array},\right.
$$


with

$$
f_{i}\left(\delta_{t}^{(i)}\right)=\left|\delta_{t}^{(i)}\right|-c_{i} \delta_{t}^{(i)}
$$

In the Eqs. (2) and (3) the quantities $\omega_{i}, \alpha_{i}, \beta_{i}, \mu_{i}$ and $\nu_{i}$ are parameters which are typically estimated from the data. The lagged variance term $h_{t-1}^{(i)}$ is an average value of the regimedependent lagged value $h_{i, t-1}$, while $\delta_{t}^{(i)}$ is an average value of the regime-dependent estimates of $\epsilon_{t}$. Both quantities will be explained below. The parameters $\mu_{i}$ and $\nu_{i}$ are shape parameters which may be predetermined in order to preselect alternative distinct and well-known GARCH models. $^{1}$ In our empirical analysis below, for example, we estimate two different Markovswitching specifications. In our first specification, a Markov-switching EGARCH-TGARCH model, we predetermine $\mu_{1}=0$ and $\nu_{1}=1$ in order to obtain an EGARCH equation in regime 1 , while we set $\mu_{2}=1$ and $\nu_{2}=1$ to obtain a TGARCH equation in regime 2 . Via this predetermination Eq. (2) becomes

$$
h_{i, t}=\left\{\begin{array}{ll}
{\left[\exp \left\{\omega_{1}+\alpha_{1} f_{1}\left(\delta_{t}^{(1)}\right)+\beta_{1} \ln \left(\sqrt{h_{t-1}^{(1)}}\right)\right\}\right]^{2}} & \text { for } \quad S_{t}=1 \\
{\left[\omega_{2}+\alpha_{2} \sqrt{h_{t-1}^{(2)}} f_{2}\left(\delta_{t}^{(2)}\right)+\beta_{2} \sqrt{h_{t-1}^{(2)}}\right]^{2}} & \text { for } \quad S_{t}=2
\end{array} .\right.
$$

In our second empirical specification, a Markov-switching TGARCH-TGARCH model, we predetermine $\mu_{1}=\mu_{2}=1$ and $\nu_{1}=\nu_{2}=1$ so that $h_{i, t}$ adapts accordingly.

The quantities $h_{t-1}^{(i)}$ and $\delta_{t}^{(i)}$ have been introduced in the above volatility equations in order to circumvent the problem of path dependence which is typically inherent in Markov-switching GARCH models. This collapsing procedure is originally due to Gray (1996) and was later refined by Klaassen (2002). Reher and Wilfling (2016) present a detailed description of how to calculate both quantities in the general Markov-switching GARCH setup stated above. For the purpose of this paper, it is sufficient to mention that for expressing $h_{t-1}^{(i)}$ and $\delta_{t}^{(i)}$ we need certain regime probabilities, denoted by $p_{1, t-1}^{(i)}$, which represent the probability that the DGP was in Regime 1 at date $t-1$ when the DGP currently (i.e. at date $t$ ) is in Regime $i$. Via these

\footnotetext{
${ }^{1}$ This general parameterization of the GARCH equation in a single-regime framework is due to Hentschel (1995).
} 
probabilities, which can be computed from Eq. (A.13) in the Appendix to this paper, we have

$$
h_{t-1}^{(i)}=p_{1, t-1}^{(i)} h_{1, t-1}+\left(1-p_{1, t-1}^{(i)}\right) h_{2, t-1}
$$

and

$$
\delta_{t}^{(i)}=p_{1, t-1}^{(i)} \frac{r_{t}-\lambda}{\sqrt{h_{1, t-1}}}+\left(1-p_{1, t-1}^{(i)}\right) \frac{r_{t}-\lambda}{\sqrt{h_{2, t-1}}} .
$$

Finally, we close our econometric model by specifying the probabilistic nature of the regime indicator $S_{t}$. To keep the analysis tractable, we model $S_{t}$ as a first-order Markov process with constant transition probabilities $\pi_{1}$ and $\pi_{2}$ :

$$
\begin{aligned}
& \operatorname{Pr}\left(S_{t}=1 \mid S_{t-1}=1\right)=\pi_{1}, \\
& \operatorname{Pr}\left(S_{t}=2 \mid S_{t-1}=1\right)=1-\pi_{1}, \\
& \operatorname{Pr}\left(S_{t}=1 \mid S_{t-1}=2\right)=1-\pi_{2}, \\
& \operatorname{Pr}\left(S_{t}=2 \mid S_{t-1}=2\right)=\pi_{2} .
\end{aligned}
$$

Our Markov-switching GARCH model established in the Eqs. (1) to (7) can now be estimated using maximum likelihood techniques. The log-likelihood function is constructed recursively and we present its exact form in the Eqs. (A.14) of the Appendix.

\section{Data and estimation results}

\subsection{Data}

On 19 September 2008 the German Federal Financial Supervisory Authority (BaFin) announced the prohibition of naked short sales of the shares for the following 11 enterprises: Aareal Bank, Allianz, AMB Generali Holding, Commerzbank, Deutsche Bank, Deutsche Börse, Deutsche Postbank, Hannover Rückversicherung, Hypo Real Estate Holding, MLP, and Münchener Rückversicherungsgesellschaft. Initially, the BaFin envisaged to sustain this short selling restriction until 31 December 2008, but then prolonged it in three steps, namely (1) until 31 March 2009, (2) until 31 May 2009, and finally (3) until 31 January 2010. Overall, this amounts to a period of 343 trading days in succession during which the restriction was in force. From 1 February 2010 onwards the BaFin lifted the restriction, but reinstalled it on 18 May 2010 for the same 
group of enterprises except for the Hypo Real Estate Holding which had ceased being listed in the meantime.

In this paper we aim at assessing the overall volatility effects of these short selling constraints, but refrain from analyzing the volatility effects on a single share. For this purpose we construct an index from the stock returns of the above-mentioned enterprises, but exclude the Hypo Real Estate Holding which was delisted during the sampling period. In what follows we refer to these 10 enterprises as our sample group. As our index weights we use daily market values which we observe between 2 January 2006 and 23 June 2010 (1136 observations).

In order to compare our volatility results with a control group we constructed a second index consisting of all DAX enterprises that were not subject to short selling constraints (i.e. which are not among the enterprises of the sample group). Additionally, we excluded Volkswagen from the control group since take-over speculation during the sampling period caused abnormal stock price behavior that might interfere with our research question.

\section{Figure 1 about here}

Figure 1 displays the daily index returns for both groups during the sampling period. In each panel we mark the two periods without and with short selling restrictions by differently colored lines with the dark line highlighting the periods subject to short selling restrictions. Both trajectories clearly exhibit volatility clustering, a prominent feature well-documented in the financial literature on asset returns dynamics. We now turn to analyzing the volatility structures in both return series within our Markov-switching GARCH framework from Section 2 .

\section{Table 1 about here}

\subsection{Estimation results}

Although the general Markov-switching GARCH framework established in Section 2 covers a broad range of distinct regime-specific GARCH equations, we restrict attention in this paper 
to two alternative Markov-switching GARCH specifications, namely an EGARCH-TGARCH and a TGARCH-TGARCH model. ${ }^{2}$ Table 1 displays the maximum likelihood (ML) estimates of both Markov-switching GARCH models - as represented by the Eqs. (1) to (7) - for the index returns of our sample and control groups. We numerically maximized the log-likelihood functions from the Eqs. (A.1) to (A.14) by the use of the BFGS-algorithm as implemented in the FMINCON module of the software package MATLAB. Our estimation results are robust to different starting values. To circumvent numerical problems stemming from the absolute value function appearing on the right-hand side of Eq. (3), we follow Hentschel (1995) and replace the argument of the absolute value function by a hyperbolic approximation. ${ }^{3}$ Standard errors were computed from the diagonal of the heteroskedasticity-consistent (White-robust) covariance matrix.

The parameter estimates and standard errors for both Markov-switching GARCH specifications reported in Table 1 can be used to assess the statistical significance of the respective model parameters. To this end, we consider the conventional $t$-statistic the exact finite-sample distribution of which is generally unknown under our estimation setup. However, we can make asymptotic inference by noticing (1) that our ML estimators are asymptotically normally distributed, and (2) that our standard errors constitute (weakly) consistent estimates of the true standard deviations of the ML estimators. Consequently, under the null hypothesis of a single parameter being equal to 0 , our $t$-statistics should converge in distribution towards a standard normal variate implying critical values of $1.6449,1.9600$ and 2.5758 at the 10,5 , and $1 \%$ levels, respectively, for the absolute value of the $t$-statistic (see Greene 2008, Appendix D). Following this reasoning, we find that 35 out of 44 parameters are significant at the $1 \%$ level.

An important issue concerns the persistence of volatility shocks. In a conventional singleregime TGARCH $(1,1)$ equation the persistence of volatility shocks is typically measured by the term $\alpha^{2}\left(1+c^{2}\right)+\beta^{2}+4 \alpha \beta \phi(0)$ (with $\phi(\cdot)$ denoting the probability density function of

\footnotetext{
${ }^{2}$ In a preliminary analysis we estimated several other Markov-switching GARCH specifications. However, we found that the EGARCH-TGARCH and the TGARCH-TGARCH specifications provide the best fit to our data.

${ }^{3}$ Technical details on the estimation procedure are available upon request.
} 
the standard normal distribution), while in a single-regime EGARCH model the persistence of volatility shocks is simply measured by the parameter $\beta$. Generally speaking, we can state that the higher the value of these terms, the longer it takes until a volatility shock dies out. In particular, when the terms are equal to 1 volatility shocks have a permanent effect and the unconditional variances of the respective processes get infinitely large.

In view of these considerations within a single-regime framework, it appears natural to measure the persistence of volatility shocks in our two-regime Markov-switching EGARCHTGARCH model by the corresponding regime-specific persistence conditions. Unfortunately, matters turn out to be more complicated, since in general it is the interaction between the regime-specific volatility parameters and the (constant) transition probabilities $\pi_{1}$ and $\pi_{2}$ of the regime indicator $S_{t}$ which determines the variance stability of a Markov-switching GARCH model. ${ }^{4}$

However, since exact mathematical conditions covering the variance-stability even of the structurally simplest Markov-switching GARCH models are not available in the literature, we are restricted to analyzing the persistence of volatility shocks within each Markov-regime (neglecting the potential impact of the interaction between the regime-specific GARCH parameters and the transition probabilities on the variance stability of the entire Markov-switching model). In Table 1 these volatility persistence measures are given in the rows 'Volatility persistence in regime 1' and 'Volatility persistence in regime 2'. Obviously, all these measures are smaller than 1 indicating that shocks do not have a permanent impact on regime-specific unconditional variances.

As a final diagnostic check of the validity of both Markov-switching GARCH specifications we may test the squared (standardized) residuals for first- and higher-order serial correlation by the Ljung-Box-Q-statistic. We performed Ljung-Box-tests for serial correlation of the squared residuals out to various lags for both Markov-switching GARCH specifications and did not find any statistical evidence of serial correlation ${ }^{5}$

\footnotetext{
${ }^{4}$ See for example, Wilfling (2009) and the literature cited there.

${ }^{5}$ Details of the autocorrelation tests are available upon request.
} 
Figure 2 about here

\subsubsection{Volatility and regime-switching results for the EGARCH-TGARCH model}

Figure 2 displays the conditional variances and regime-1 probabilities for the sample group (left panels) and the control group (right) panels as estimated by our Markov-switching EGARCHTGARCH specification. We depict two distinct regime-1 probabilities for both groups, namely the ex ante regime- 1 probabilities $p_{1, t}=\operatorname{Pr}\left\{S_{t}=1 \mid \phi_{t}\right\}$ as estimated according to Eq. (A.8) of the appendix (thin lines) and the so-called smoothed regime-1 probabilities $\operatorname{Pr}\left\{S_{t}=1 \mid \phi_{T}\right\}$ which we computed as described in Hamilton (1994).

Figure 2 provides evidence that the short selling restrictions rather have a destabilizing than a stabilizing impact on return volatility. The conditional variances have a distinctive peak in both the sample and the control group after the short selling restrictions have come into operation. The peak in the sample group is even higher in absolute value than in the control group, but the overall volatility level has already been higher in the sample group prior to the prohibition of naked short sales. For the sample group we observe a second clear-cut peak in the conditional variances in March/April 2009. This large volatility increase has no counterpart in the control group. From this we might conjecture (1) that the first peak may have been caused by the outbreak of the financial crisis and (2) that there is no evidence that the short selling restrictions may have stabilized return volatility in our sample group. The second volatility peak in March/April 2009 rather appears to indicate that the return variances of the sample group have been destabilized.

The regime- 1 probabilities in Figure 2 indicate two substantial changes in the return dynamics for both the sample and the control group. The first striking regime-switch from Regime 2 to Regime 1 occurs in September 2006 for the sample group, when international market participants became aware of the first signals of the subprime crisis, and in January/February 2007 for the control group. The second switch from Regime 2 to Regime 1 occurred in August 2008 for the sample group and in January 2009 for the control group. Obviously, the regime switches in the control group occur later than their counterparts for the sample group. A plausible expla- 
nation of this phenomenon is that the financial sector - represented by our sample group - was immediately affected by the financial crisis whereas the nonfinancial enterprises in our control group were affected with a delay. Apart from the switches from Regime 2 to Regime 1 , the regime-1 probabilities for the sample group exhibit a switch back from Regime 1 to Regime 2 at the beginning of the restriction period. This switch happened precisely on 18 December 2008 when the BaFin announced the first prolongation of the short selling restrictions.

There are two justifications as to why the aforementioned regime switches are likely to have stemmed from other effects than the short selling restrictions. First, we observe analogous regime-switches also for the control group, and second we observe an analogous regime switch for the sample group during a period long before the short selling restrictions came into operation.

There is, however, a clear-cut empirical argument in favor of the hypothesis that the short selling restrictions might have had a rather destabilizing than a stabilizing effect on the return volatility of the sample group. We base our reasoning on the volatility persistence estimates in both Markov-regimes as displayed in the lower part of Table 1. We interpret a high (low) value of the regime-specific volatility persistence as an indicator of low (high) variance stability. For the sample group the volatility persistence in Regime 1 is 0.9951 exceeding the corresponding regime-1 volatility persistence of the control group which is 0.9824 . In contrast to this, the volatility persistence in Regime 2 for the sample group is 0.9063 and thus lower than the regime-2 volatility persistence for the control group which is 0.9185 . Consequently, for our sample group the regime switch from Regime 2 to Regime 1 entails a higher increase in volatility persistence than for our control group indicating a relatively stronger variance destabilization in Regime 1 for the sample group as compared to the control group.

Figure 3 about here

\subsubsection{Volatility and regime-switching results for the TGARCH-TGARCH model}

Figure 3 displays the regime-1 probabilities and conditional variances of our Markov-Switching TGARCH-TGARCH model. As within our EGARCH-TGARCH framework from Section 3.2.1, 
Figure 3 again does not provide any evidence that the short selling restrictions may have had a stabilizing effect on return volatility. The conditional variances are qualitatively similar to those of the EGARCH-TGARCH model with a clear-cut peak for both groups after the short selling restrictions have come into operation. The volatility peak in the sample group is again higher than in the control group and the relative increase in the conditional variances of the sample group as compared to the variance increase of the control group is even larger than within the EGARCH-TGARCH framework. Consequently, we are inclined to draw the same conclusions as in Section 3.2.1.

For the sample group the regime- 1 probabilities in Figure 3 indicate a switch from Regime 2 to Regime 1 during the period of the short selling restrictions. There is a switch back to Regime 2 shortly before the short selling restrictions expire. This might indicate that market participants anticipate that there will be no further prolongation of the restriction period. By contrast, the regime probabilities of the control group do not exhibit such distinctive switches. However, during the period of the short selling restrictions the control group is also in Regime 1 most of the time.

Finally, we consider again the volatility persistence in both Markov-regimes which we interpret as a measure of variance stability. According to the lower part of Table 1 the regime-1 volatility persistence for the sample group is 0.9852 again (slightly) exceeding the corresponding regime- 1 volatility persistence of the control group which is 0.9831 . In Regime 2 the volatility persistence of the sample group is 0.8733 and hence is substantially lower than the volatility persistence for the control group which is 0.9313 . Consequently, the switch from Regime 2 to Regime 1 during the period of short selling restrictions again constitutes a transition into a highly destabilized volatility regime. This is particularly true for our sample group for which we find an extreme increase in volatility persistence from 0.8733 to 0.9852 . 


\section{Conclusions}

In this paper we analyze the impact of short selling restrictions on stock returns volatility for the German stock market. To this end, we construct an index from those stocks on which the German Federal Financial Supervisory Authority (BaFin) imposed short selling constraints during the years 2008 until 2010. As a control group we consider an index constructed from all DAX enterprises that were not subject to short selling constraints.

Estimating two distinct versions of a two-regime Markov switching asymmetric GARCH model (an EGARCH-TGARCH and a TGARCH-TGARCH specification) for the stock returns of both indices, we observe an overall increase in the conditional variances for the whole German stock market after the collapse of Lehman Brothers. However, we find econometric evidence that the financial crisis is accompanied by an increase in volatility persistence and that this effect is particularly pronounced for those stocks that were subject to short selling constraints. We interpret this finding as evidence of a destabilizing impact of short selling constraints on stock returns volatility.

A natural line of future research could be an investigation on the impact of short selling constraints on the trading volume. An analysis of this issue could possibly reveal two aspects. First, market participants are likely to circumvent the short selling restriction through the evasion in derivatives and a switch to alternative market places in which no short selling

restrictions are in force. Second, short selling constraints might entail substantial changes in liquidity. Apart from that a quantitative analysis as to what extent short selling constraints on selected shares can erode investors' confidence in the affected enterprises and thus induce stock price declines appears to be indicated.

\section{Appendix A. Maximum likelihood estimation}

In this appendix we construct the log-likelihood function for the Markov-switching EGARCHTGARCH model established in Section 2. The log-likelihood function for the TGARCH- 
TGARCH model may be similarly derived by inserting the corresponding functional form in the GARCH equation (A.10) below.

The conditional probability distribution of $r_{t+1}$ is given by

$$
r_{t+1} \mid \phi_{t} \sim \begin{cases}N\left(\lambda, h_{1, t}\right) & \text { with probability } p_{1, t} \\ N\left(\lambda, h_{2, t}\right) & \text { with probability }\left(1-p_{1, t}\right)\end{cases}
$$

where $\phi_{t}$ defines the information set as of date $t$ and $p_{i, t} \equiv \operatorname{Pr}\left\{S_{t}=i \mid \phi_{t}\right\}$ denotes the so-called ex-ante probability of being in regime $i$ at date $t$. It is instructive to note that the information set $\phi_{t}$ basically coincides with the return path $\tilde{r}_{t}=\left\{r_{t}, r_{t-1}, \ldots\right\}$, but does not contain the path of the unobservable regime indicator $S_{t}$. The corresponding probability density function has the form

$$
\begin{aligned}
f\left(r_{t+1} \mid \phi_{t}\right) & =\sum_{i=1}^{2} f\left(r_{t+1}, S_{t}=i \mid \phi_{t}\right) \\
& =\sum_{i=1}^{2} \operatorname{Pr}\left(S_{t}=i \mid \phi_{t}\right) \cdot f\left(r_{t+1} \mid S_{t}=i, \phi_{t}\right) \\
& =\sum_{i=1}^{2} p_{i, t} \cdot f\left(r_{t+1} \mid S_{t}=i, \phi_{t}\right) .
\end{aligned}
$$

Since the regime indicator $S_{t}$ follows a first-order Markov process the ex-ante probability $p_{i, t}$ depends only on $S_{t-1}$. Using the Theorem of Total Probabilities, we obtain

$$
p_{i, t}=\sum_{j=1}^{2} \operatorname{Pr}\left(S_{t}=i \mid S_{t-1}=j, \tilde{r}_{t}\right) \operatorname{Pr}\left(S_{t-1}=j \mid \tilde{r}_{t}\right) .
$$

The first probability $\operatorname{Pr}\left(S_{t}=i \mid S_{t-1}=j, \tilde{r}_{t}\right)$ on the right-hand side of (A.3) does not depend on $\tilde{r}_{t}$. Thus, we can insert the probabilities specified in Eq. (7) in Eq. (A.3) and obtain

$$
\begin{aligned}
p_{1, t} & =\pi_{1} \cdot \operatorname{Pr}\left(S_{t-1}=1 \mid \tilde{r}_{t}\right)+\left(1-\pi_{2}\right) \cdot \operatorname{Pr}\left(S_{t-1}=2 \mid \tilde{r}_{t}\right) \\
& =\pi_{1} \cdot \operatorname{Pr}\left(S_{t-1}=1 \mid \tilde{r}_{t}\right)+\left(1-\pi_{2}\right) \cdot\left(1-\operatorname{Pr}\left(S_{t-1}=1 \mid \tilde{r}_{t}\right)\right),
\end{aligned}
$$


and analogously

$$
p_{2, t}=\pi_{2} \cdot\left(1-\operatorname{Pr}\left(S_{t-1}=1 \mid \tilde{r}_{t}\right)\right)+\left(1-\pi_{1}\right) \cdot \operatorname{Pr}\left(S_{t-1}=1 \mid \tilde{r}_{t}\right) .
$$

The remaining probability $\operatorname{Pr}\left(S_{t-1}=1 \mid \tilde{r}_{t}\right)$ in the Eqs. (A.4) and (A.5) can be written as a function of $p_{1, t-1}=\operatorname{Pr}\left(S_{t-1}=1 \mid \tilde{r}_{t-1}\right)$. To this end, we apply Bayes' Formula yielding

$$
\begin{aligned}
\operatorname{Pr}\left(S_{t-1}=1 \mid \tilde{r}_{t}\right) & =\operatorname{Pr}\left(S_{t-1}=1 \mid r_{t}, \tilde{r}_{t-1}\right) \\
& =\frac{f\left(r_{t} \mid S_{t-1}=1, \tilde{r}_{t-1}\right) \operatorname{Pr}\left(S_{t-1}=1, \tilde{r}_{t-1}\right)}{\sum_{i=1}^{2} f\left(r_{t} \mid S_{t-1}=i, \tilde{r}_{t-1}\right) \operatorname{Pr}\left(S_{t-1}=i, \tilde{r}_{t-1}\right)} .
\end{aligned}
$$

Expanding the ratio on the right-hand side of Eq. (A.6), we obtain

$$
\begin{aligned}
\operatorname{Pr}\left(S_{t-1}=1 \mid \tilde{r}_{t}\right) & =\frac{f\left(r_{t} \mid S_{t-1}=1, \tilde{r}_{t-1}\right) \operatorname{Pr}\left(S_{t-1}=1 \mid \tilde{r}_{t-1}\right)}{\sum_{i=1}^{2} f\left(r_{t} \mid S_{t-1}=i, \tilde{r}_{t-1}\right) \operatorname{Pr}\left(S_{t-1}=i \mid \tilde{r}_{t-1}\right)} \\
& =\frac{f\left(r_{t} \mid S_{t-1}=1, \tilde{r}_{t-1}\right) p_{1, t-1}}{\sum_{i=1}^{2} f\left(r_{t} \mid S_{t-1}=i, \tilde{r}_{t-1}\right) p_{i, t-1}} \\
& =\frac{g_{1, t-1} \cdot p_{1, t-1}}{\sum_{i=1}^{2} g_{i, t-1} \cdot p_{i, t-1}},
\end{aligned}
$$

where, for ease of notation, we have defined $g_{i, t-1} \equiv f\left(r_{t} \mid S_{t-1}=i, \tilde{r}_{t-1}\right)=f\left(r_{t} \mid S_{t-1}=i, \phi_{t-1}\right)$. Using Eq. (A.7), we are now able to calculate the ex-ante probability $p_{1, t}$ by inserting Eq. (A.7) in Eq. (A.4):

$$
\begin{aligned}
p_{1, t} & =\pi_{1} \cdot \frac{g_{1, t-1} p_{1, t-1}}{g_{1, t-1} p_{1, t-1}+g_{2, t-1}\left(1-p_{1, t-1}\right)}+\left(1-\pi_{2}\right) \cdot\left[1-\frac{g_{1, t-1} p_{1, t-1}}{g_{1, t-1} p_{1, t-1}+g_{2, t-1}\left(1-p_{1, t-1}\right)}\right] \\
& =\pi_{1} \cdot \frac{g_{1, t-1} p_{1, t-1}}{g_{1, t-1} p_{1, t-1}+g_{2, t-1}\left(1-p_{1, t-1}\right)}+\left(1-\pi_{2}\right) \cdot \frac{g_{2, t-1}\left(1-p_{1, t-1}\right)}{g_{1, t-1} p_{1, t-1}+g_{2, t-1}\left(1-p_{1, t-1}\right)} \cdot \quad(\mathrm{A} .8)
\end{aligned}
$$

Next, we address the exact form of the conditional density $f$ appearing in the Eqs. (A.2) and (A.8). Since we assume conditional normality $f$ is given as

$$
f\left(r_{t+1} \mid S_{t}=i, \phi_{t}\right)=\frac{1}{\sqrt{2 \pi h_{i, t}}} \exp \left\{-\frac{\left(r_{t+1}-\lambda\right)^{2}}{2 h_{i, t}}\right\} .
$$


The variance $h_{i, t}$ depends on the explicit functional form of the GARCH equation. In the case of our EGARCH-TGARCH specification we set $\mu_{1}=0, \nu_{1}=1, \mu_{2}=1$ and $\nu_{2}=1$ in Eq. (2) of the main text and obtain

$$
h_{i, t}= \begin{cases}{\left[\exp \left\{\omega_{1}+\alpha_{1} f_{1}\left(\delta_{t}^{(1)}\right)+\beta_{1} \ln \left(\sqrt{h_{t-1}^{(1)}}\right)\right\}\right]^{2}} & \text { for } \quad S_{t}=1 \\ {\left[\omega_{2}+\alpha_{2} \sqrt{h_{t-1}^{(2)}} f_{2}\left(\delta_{t}^{(2)}\right)+\beta_{2} \sqrt{h_{t-1}^{(2)}}\right]^{2}} & \text { for } \quad S_{t}=2\end{cases}
$$

with appropiately defined parameters $\omega_{i}, \alpha_{i}, \beta_{i}$.

It is obvious from Eq. (A.10) that for the calculation of regime-specific variances $h_{i, t}$ we need the aggregated variances and shock terms $h_{t-1}^{(i)}$ and $\delta_{t}^{(i)}$ the calculation of which we base on the probabilities $p_{1, t-1}^{(i)}$ as described in the main text. Using Bayes' Formula once more, we obtain these probabilities as

$$
\begin{aligned}
p_{1, t-1}^{(i)} & =\operatorname{Pr}\left(S_{t-1}=1 \mid \tilde{r}_{t-1}, S_{t}=i\right) \\
& =\frac{\operatorname{Pr}\left(S_{t}=i \mid \tilde{r}_{t-1}, S_{t-1}=1\right) \operatorname{Pr}\left(S_{t-1}=1 \mid \tilde{r}_{t-1}\right)}{\operatorname{Pr}\left(S_{t}=i \mid \tilde{r}_{t-1}\right)} \\
& =\frac{\operatorname{Pr}\left(S_{t}=i \mid \tilde{r}_{t-1}, S_{t-1}=1\right) \cdot p_{1, t-1}}{\operatorname{Pr}\left(S_{t}=i \mid \tilde{r}_{t-1}\right)}
\end{aligned}
$$

with $p_{1, t-1}$ as given in Eq. (A.8). Using the Theorem of Total Probabilities, we write the denominator in Eq. (A.11) as

$$
\begin{aligned}
\operatorname{Pr}\left(S_{t}=i \mid \tilde{r}_{t-1}\right)= & \operatorname{Pr}\left(S_{t}=i \mid \tilde{r}_{t-1}, S_{t-1}=1\right) \cdot p_{1, t-1} \\
& +\operatorname{Pr}\left(S_{t}=i \mid \tilde{r}_{t-1}, S_{t-1}=2\right) \cdot\left(1-p_{1, t-1}\right) .
\end{aligned}
$$

To calculate the probability on the left-hand of Eq. (A.11) we need the two probabilities $\operatorname{Pr}\left(S_{t}=\right.$ $\left.i \mid \tilde{r}_{t-1}, S_{t-1}=1\right)$ and $\operatorname{Pr}\left(S_{t}=i \mid \tilde{r}_{t-1}, S_{t-1}=2\right)$. These probabilities coincide with those defined in Eq. (7) of the main text, since the Markov process is independent of the return process. 
Now, inserting the Eqs. (7) and (A.12) in Eq. (A.11), we obtain

$$
\begin{aligned}
& p_{1, t-1}^{(1)}=\frac{\pi_{1} \cdot p_{1, t-1}}{\pi_{1} \cdot p_{1, t-1}+\left(1-\pi_{2}\right) \cdot p_{2, t-1}}, \\
& p_{2, t-1}^{(1)}=1-p_{1, t-1}^{(1)}, \\
& p_{1, t-1}^{(2)}=\frac{\left(1-\pi_{1}\right) \cdot p_{1, t-1}}{\left(1-\pi_{1}\right) \cdot p_{1, t-1}+\pi_{2} \cdot p_{2, t-1}}, \\
& p_{2, t-1}^{(2)}=1-p_{1, t-1}^{(2)} .
\end{aligned}
$$

Finally, we use the recursive structures developed so far to construct the log-likelihood function of our Markov-switching model defined in the Eqs. (1) to (7). The general form of the likelihood function is

$$
L(\boldsymbol{\Theta})=f\left(r_{t}, \ldots, r_{1} ; \boldsymbol{\Theta}\right)
$$

with the vector $\Theta$ containing all model parameters. Writing this joint distribution of the returns as a product of conditional densities, we obtain

$$
L(\boldsymbol{\Theta})=\prod_{t=1}^{T} f\left(r_{t} \mid \tilde{r}_{t-1} ; \boldsymbol{\Theta}\right)
$$

for which we define the starting term as $f\left(r_{1} \mid \tilde{r}_{0} ; \boldsymbol{\Theta}\right) \equiv f\left(r_{1} ; \boldsymbol{\Theta}\right)$. Taking the logarithm of $L(\boldsymbol{\Theta})$ and inserting (the lagged form of) Eq. (A.1), we obtain the log-likelihood function as

$$
\begin{aligned}
\ell(\boldsymbol{\Theta}) \equiv \log [L(\boldsymbol{\Theta})] & =\sum_{t=1}^{T} \log \left[f\left(r_{t} \mid \tilde{r}_{t-1} ; \boldsymbol{\Theta}\right)\right] \\
& =\sum_{t=1}^{T} \log \left[\sum_{j=1}^{2} f\left(r_{t} \mid S_{t-1}=j, \tilde{r}_{t-1} ; \boldsymbol{\Theta}\right) \cdot p_{j, t-1}\right]
\end{aligned}
$$




\section{References}

Beber, A., Fabbri, D., Pagano, M., 2015. Short-selling bans and bank stability. CSEF Working Paper No. 423, Centre for Studies in Economics and Finance (CSEF), University of Naples.

Boehmer, E., Huszar, Z. R., Wang, Y., Zhang, X., 2015. Are shorts equally informed? A global perspective. Unpublished Working Paper.

Bohl, M.T., Diesteldorf, J., Salm, C.A., Wilfling, B., 2016. Spot market volatility and futures trading: The pitfalls of using a dummy variable approach. Journal of Futures Markets $36,30-45$.

Bohl, M.T., Essid, B., Siklos, P.L., 2012. Do short selling restrictions destabilize stock markets? Lessons from Taiwan. The Quarterly Review of Economics and Finance 52, 198- 206.

Bris, A., Goetzman, W. N., Zhu, N., 2007. Efficiency and the bear: Short sales and markets around the world. Journal of Finance 62, 1029 - 1079.

Gray, S.F., 1996. Modeling the conditional distribution of interest-rates as a regime-switching process. Journal of Financial Economics 3, 59-71.

Greene, W.H., 2008. Econometric Analysis. Pearson Education, New Jersey.

Hamilton, J.D., 1994. Time Series Analysis. Princeton University Press, Princeton.

Hentschel, L., 1995. All in the family: Nesting symmetric and asymmetric GARCH models. Journal of Financial Economics 39, 71-104.

Klaasen, F., 2002. Improving GARCH volatility forecasts with regime-switching GARCH. Empirical Economics 27, 363-394.

Nelson, D.B., 1991. Conditional heteroskedasticity in asset returns: a new approach. Econometrica 59, 347-370.

Reher, G., Wilfling, B., 2016. A nesting framework for Markov-switching GARCH modelling with an application to the German stock market. Quantitative Finance, forthcoming.

Wilfling, B., 2009. Volatility regime-switching in European exchange rates prior to monetary unification. Journal of International Money and Finance 28, 240-270. 
Zakoian, J.M., 1994. Threshold heteroscedastic models. Journal of Economic Dynamics and Control 18, 931-955. 
Figures and Tables 

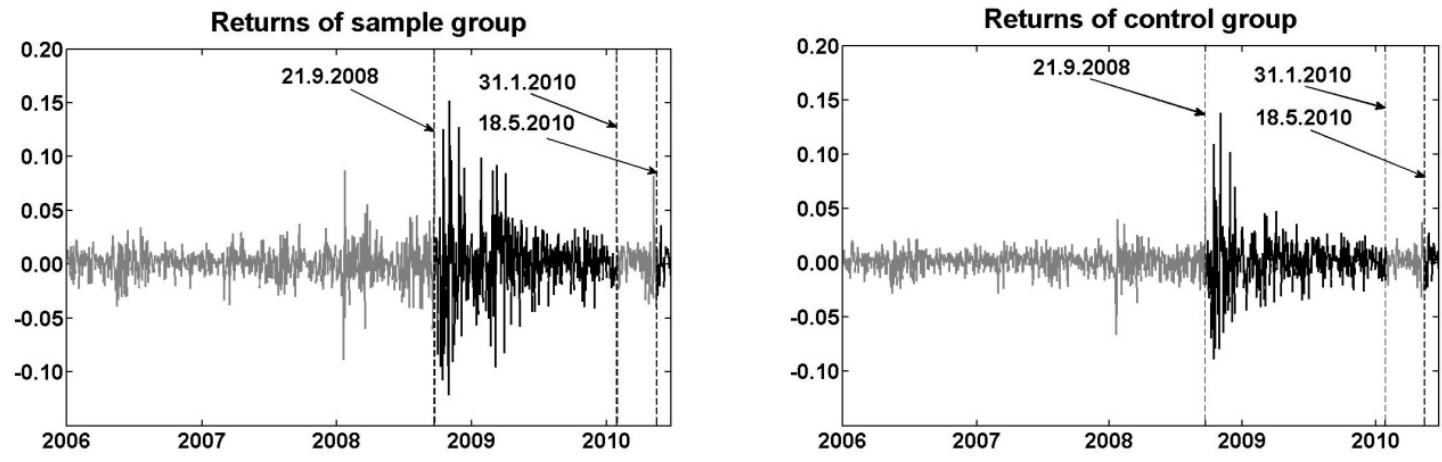

Figure 1: Daily index returns for the sample and the control group 

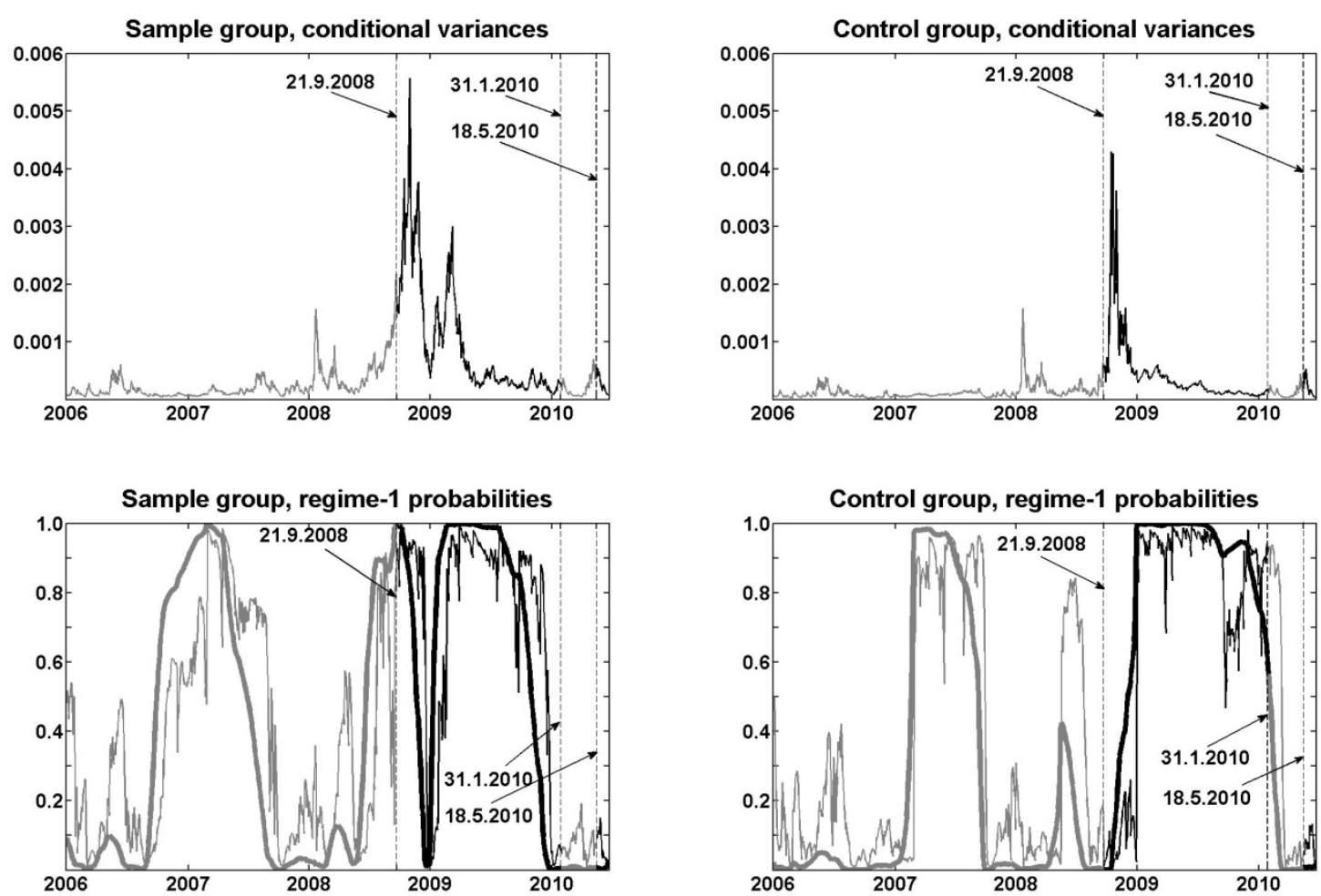

Figure 2: Conditional variances and regime-1 probabilities for the sample and the control group estimated by the Markov-switching EGARCH-TGARCH specification 

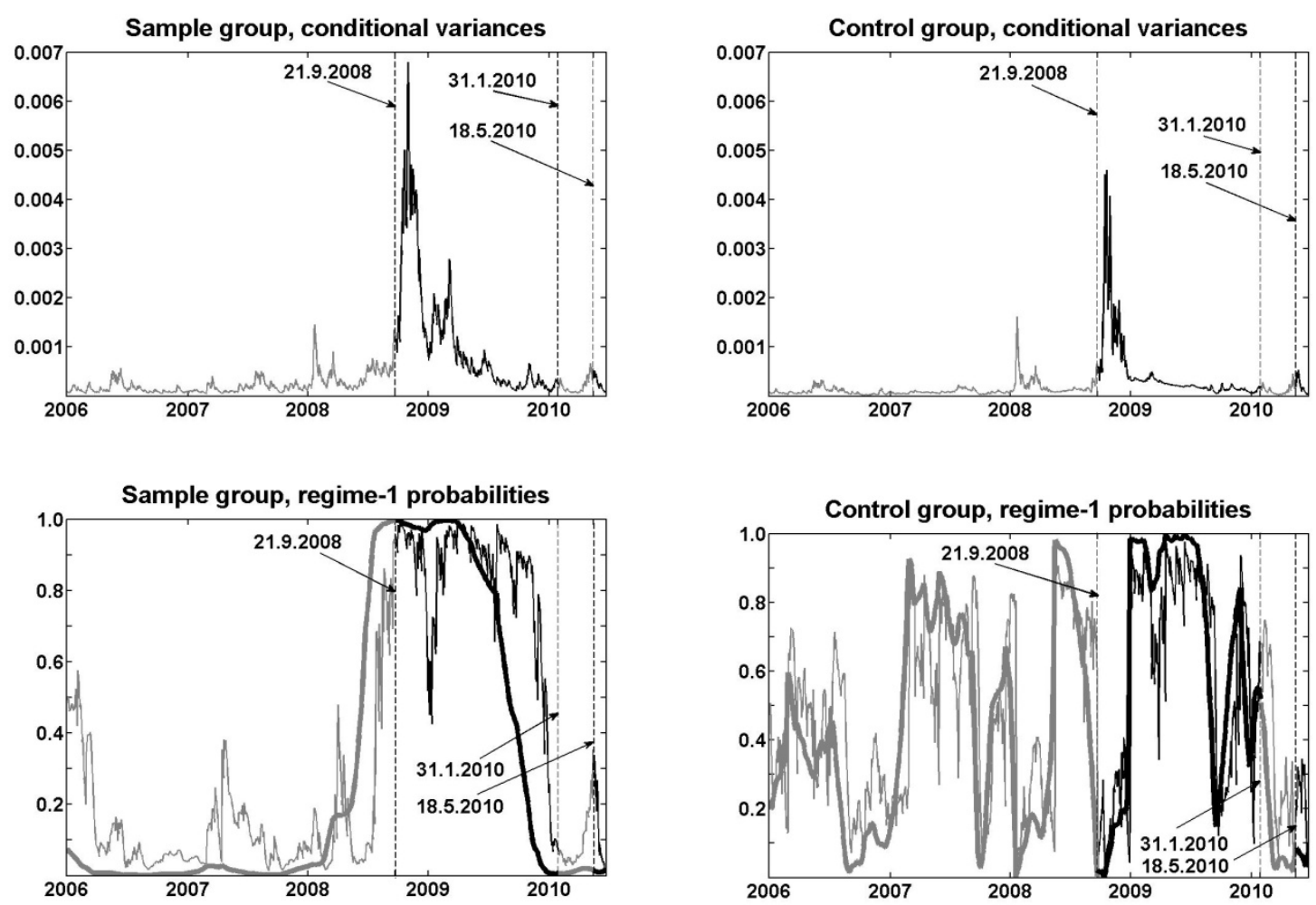

Figure 3: Conditional variances and regime-1 probabilities for the sample and the control group estimated by the Markov-switching TGARCH-TGARCH specification 
Table 1

Estimates of EGARCH-TGARCH and the TGARCH-TGARCH model for the sample group and the control group

\begin{tabular}{|c|c|c|c|c|}
\hline & $\begin{array}{l}\text { Sample group } \\
\text { EGARCH- } \\
\text { TGARCH }\end{array}$ & $\begin{array}{l}\text { Control group } \\
\text { EGARCH- } \\
\text { TGARCH }\end{array}$ & $\begin{array}{l}\text { Sample group } \\
\text { TGARCH- } \\
\text { TGARCH }\end{array}$ & $\begin{array}{l}\text { Control group } \\
\text { TGARCH- } \\
\text { TGARCH }\end{array}$ \\
\hline$\overline{\mu_{1}}$ & 0.0000 & 0.0000 & 1.0000 & 1.0000 \\
\hline$\mu_{2}$ & 1.0000 & 1.0000 & 1.0000 & 1.0000 \\
\hline$\nu_{1}$ & 1.0000 & 1.0000 & 1.0000 & 1.0000 \\
\hline$\nu_{2}$ & 1.0000 & 1.0000 & 1.0000 & 1.0000 \\
\hline$\lambda$ & $\begin{array}{r}-0.0000 \\
(0.0015)\end{array}$ & $\begin{array}{c}0.0002 \\
(0.0067)\end{array}$ & $\begin{array}{c}0.0000 \\
(0.0001)\end{array}$ & $\begin{array}{c}0.0004 \\
(0.0015)\end{array}$ \\
\hline$\omega_{1}$ & $\begin{array}{l}0.0158^{* * *} \\
(0.0012)\end{array}$ & $\begin{array}{r}-0.0336 \\
(0.0234)\end{array}$ & $\begin{array}{l}0.0004^{* * *} \\
(0.0000)\end{array}$ & $\begin{array}{c}0.0001 \\
(0.0002)\end{array}$ \\
\hline$\omega_{2}$ & $\begin{array}{c}0.0007 \\
(0.0010)\end{array}$ & $\begin{array}{c}0.0006 \\
(0.0010)\end{array}$ & $\begin{array}{l}0.0010^{* * *} \\
(0.0000)\end{array}$ & $\begin{array}{c}0.0006 \\
(0.0004)\end{array}$ \\
\hline$\alpha_{1}$ & $\begin{array}{l}-0.0409^{* * *} \\
(0.0014)\end{array}$ & $\begin{array}{l}-0.0528^{* * *} \\
(0.0171)\end{array}$ & $\begin{array}{l}0.0672^{* * *} \\
(0.0002)\end{array}$ & $\begin{array}{l}0.0118^{* * *} \\
(0.0006)\end{array}$ \\
\hline$\alpha_{2}$ & $\begin{array}{l}0.0991^{* * *} \\
(0.0050)\end{array}$ & $\begin{array}{l}0.1418^{* * *} \\
(0.0420)\end{array}$ & $\begin{array}{l}0.0935^{* * *} \\
(0.0003)\end{array}$ & $\begin{array}{l}0.1443^{* * *} \\
(0.0041)\end{array}$ \\
\hline$\beta_{1}$ & $\begin{array}{l}0.9951^{* * *} \\
(0.0000)\end{array}$ & $\begin{array}{l}0.9824^{* * *} \\
(0.0000)\end{array}$ & $\begin{array}{l}0.9358^{* * *} \\
(0.0023)\end{array}$ & $\begin{array}{l}0.9820^{* * *} \\
(0.0134)\end{array}$ \\
\hline$\beta_{2}$ & $\begin{array}{l}0.8661^{* * *} \\
(0.0559)\end{array}$ & $\begin{array}{l}0.8309^{* * *} \\
(0.0214)\end{array}$ & $\begin{array}{l}0.8535^{* * *} \\
(0.0040)\end{array}$ & $\begin{array}{l}0.8350^{* * *} \\
(0.0491)\end{array}$ \\
\hline$\pi_{1}$ & $\begin{array}{l}0.9941^{* * *} \\
(0.0001)\end{array}$ & $\begin{array}{l}0.9956^{* * *} \\
(0.0238)\end{array}$ & $\begin{array}{l}0.9958^{* * *} \\
(0.0000)\end{array}$ & $\begin{array}{l}0.9845^{* * *} \\
(0.0001)\end{array}$ \\
\hline$\pi_{2}$ & $\begin{array}{l}0.9946^{* * *} \\
(0.0001)\end{array}$ & $\begin{array}{l}0.9963^{* * *} \\
(0.0299)\end{array}$ & $\begin{array}{l}0.9982^{* * *} \\
(0.0000)\end{array}$ & $\begin{array}{l}0.9851^{* * *} \\
(0.0053)\end{array}$ \\
\hline$c_{1}$ & $\begin{array}{l}-1.7014^{* * *} \\
(0.0009)\end{array}$ & $\begin{array}{l}-0.6443^{* * *} \\
(0.0444)\end{array}$ & $\begin{array}{l}1.0000^{* * *} \\
(0.0027)\end{array}$ & $\begin{array}{l}1.0000^{* * *} \\
(0.0721)\end{array}$ \\
\hline$c_{2}$ & $\begin{array}{l}0.9778^{* * *} \\
(0.1598)\end{array}$ & $\begin{array}{l}0.9975^{* * *} \\
(0.3074)\end{array}$ & $\begin{array}{l}1.0000^{* * *} \\
(0.0035)\end{array}$ & $\begin{array}{l}1.0000^{* * *} \\
(0.0202)\end{array}$ \\
\hline $\begin{array}{l}\text { Volatility persistence } \\
\text { in regime } 1\end{array}$ & 0.9951 & 0.9824 & 0.9852 & 0.9831 \\
\hline $\begin{array}{l}\text { Volatility persistence } \\
\text { in regime } 2\end{array}$ & 0.9063 & 0.9185 & 0.8733 & 0.9313 \\
\hline
\end{tabular}

